\title{
Profil Pasien Sakit Kritis yang Dirawat di Pediatric Intensive Care Unit Rumah Sakit Cipto Mangunkusumo berdasar Sistem Skoring Pediatric Logistic Organ Dysfunction-2
}

Rismala Dewi, Fatimatuzzuhroh

Departemen Ilmu Kesehatan Anak Fakultas Kedokteran Universitas Indonesia/RS Dr. Cipto Mangunkusumo, Jakarta

Latar belakang. Skor PELOD-2 digunakan untuk mengetahui disfungsi organ pada anak dengan sakit kritis. Hasil skor PELOD-2 tidak selalu berbanding lurus dengan luaran perawatan anak sakit kritis sehingga tidak selalu dapat digunakan sebagai prediktor luaran dan mortalitas anak yang dirawat di PICU.

Tujuan. Mengetahui profil dan luaran pasien sakit kritis yang dirawat berdasar skor PELOD-2.

Metode. Penelitian dilakukan secara retrospektif dengan mengambil data rekam medis pasien rawat di ruang intensif anak RSUPN Cipto Mangukusumo, sejak Januari sampai Desember 2018. Pengambilan subjek secara total sampling, penilaian dilakukan pada 24 jam pertama perawatan.

Hasil. Diperoleh 477 subjek yang memenuhi kriteria. Subjek sebagian besar berjenis kelamin laki-laki $(56,4 \%)$, berusia $<1$ tahun $(27,9 \%)$, dengan bedah sebagai diagnosis awal terbanyak (65\%). Sebagian besar pasien memiliki penyakit kronik (70,4\%). Angka mortalitas penelitian ini adalah 10,7\%. Mayoritas subjek memiliki lama rawat $\leq 7$ hari $(75,5 \%)$. Subjek dengan lama rawat $>14$ hari memiliki median skor PELOD-2 tiga kali lipat dari subjek dengan lama rawat $\leq 7$ hari. Titik potong luaran mortalitas skor PELOD-2 pada penelitian ini adalah $\geq 5$, memiliki spesifisitas $84,5 \%$ dan sensitifitas $84,3 \%$ dengan nilai AUC skor PELOD-2 dari kurva ROC sebesar 93,4\% (IK 95\% 90,6-96,2).

Kesimpulan. Skor PELOD-2 dapat digunakan untuk memprediksi disfungsi organ yang mengancam kehidupan pada anak tanpa imunosupresi dan semakin tinggi skor PELOD-2 akan diikuti dengan peningkatan lama rawat dan mortalitas. Sari Pediatri 2019;21(1):37-43

Kata kunci: PELOD-2, disfungsi organ, mortalitas, anak

\section{Critically Ill Patient's Profile in Pediatric Intensive Care Unit Cipto Mangunkusumo Hospital Based on Pediatric Logistic Organ Dysfunction-2}

Rismala Dewi, Fatimatuzzuhroh

Background. PELOD-2 score is stated can be used to discover organ dysfunction in critically ill child. PELOD-2 score does not always directly proportional to critically ill child's outcome, therefore sometimes cannot be used as outcome and mortality predictor. Objective. To describe critically ill patient's profile and outcome of based on PELOD-2 score.

Methods. This descriptive study was retrospective, conducted from January to December 2018 in Intensive Care Unit (ICU) of RSUPN Cipto Mangunkusumo. The selection of subject was total sampling and evaluation of PELOD-2 score was performed in the first 24 hours.

Results. There were 477 subjects that fulfilled the criteria. Most of the subjects were boys (56,4\%) and under 1 year of age (27,9\%) with surgical as the most common diagnosis (65\%). Most of the subject has chronic illness as comorbid (70,4\%). Mortality rate for this study is 10,7\%. Most of the subjects have stayed in PICU for $\leq 7$ days $(75,5 \%)$. Subjects with length of stay $>14$ days had median PELOD-2 score 3 times higher than the subjects with length of stay $\leq 7$ days. Mortality cut off point for PELOD-2 score in this study is $>5$, with specificity of $84,5 \%$ and sensitivity of $84,3 \%$, AUC value for PELOD-2 score from ROC curve is $93,4 \%$ (CI 95\% 90,6-96,2).

Conclusion. PELOD-2 score is feasible to be used to predict life-threatening organ dysfunction in critically ill children without immunosuppression and the higher the PELOD-2 score is equal to higher mortality and longer length of stay.Sari Pediatri 2019;21(1): $37-43$

Keyword: PELOD-2, organ dysfunction, mortality, pediatric

Alamat korespondensi: Rismala Dewi. Departemen Ilmu Kesehatan Anak Fakultas Kedokteran Universitas Indonesia/RS Dr. Cipto Mangunkusumo Jakarta. Email: dewi22juli@gmail.com 
Rismala Dewi dkk: Profil pasien sakit kritis yang dirawat di PICU RSCM berdasar sistem skoring PELOD-2

S indrom disfungsi organ multipel merupakan salah satu penanda keparahan suatu penyakit dan merupakan penyebab utama kematian pada PICU. ${ }^{1,2}$ Hingga saat ini untuk menilai derajat keparahan sakit sebagai salah satu faktor prognostik luaran pasien sakit kritis digunakan sistem skoring. ${ }^{3,4}$ Pengujian dilakukan pada beberapa skoring. Berdasarkan hasil uji beberapa skoring didapatkan sensitivitas dan spesifisitas terbaik adalah Logistic Organ Dysfunction Score (PELODS) dengan area under the curve (AUC) 0,75 dengan interval kepercayaan (IK95\% 0,73-0,76). ${ }^{5}$

Skoring LODS pada anak dikenal dengan PELODS. Skor PELOD merupakan suatu sistem skoring yang digunakan untuk mengetahui beratnya disfungsi organ pada sanak dengan sakit kritis dan memberikan gambaran deskriptif mengenai luaran anak sakit kritis yang dirawat di PICU. ${ }^{6}$ Sebuah penelitian menemukan bahwa anak sepsis dengan nilai skor PELOD 20 akan memiliki risiko mortalitas sebesar 50\%, dan semakin tinggi skor PELOD, probabilitas mortalitas akan semakin meningkat (sensitivitas 54,5\% dan spesifisitas 80,9\%; $\mathrm{p}<0,05){ }^{7}$ $\mathrm{Hal}$ ini menunjukkan bahwa semakin besar efek akumulasi disfungsi organ dan beratnya sepsis, risiko mortalitas akan semakin meningkat. Skor PELOD-2 dibuat sebagai pembaharuan dari skor PELOD karena kinerjanya dianggap kurang baik. ${ }^{8}$

Penelitian mengenai validitas skor PELOD-2 telah dilakukan di Indonesia tahun 2017 dengan nilai diskriminasi 85,5\% (IK 95\%: 74,5-96,5), kalibrasi $0,728$ ( $p>0,05)$ sesuai dengan uji Hosmer and Lemeshow, dengan uji pengaruh signifikan $\mathrm{p}<0,05 .{ }^{9}$ Hal ini berarti validitas skor PELOD-2 adalah baik. Sistem skoring PELOD-2 memudahkan penilaian keparahan kasus disfungsi multi organ di PICU dengan skala berkelanjutan. ${ }^{8}$

Divisi Emergensi dan Rawat Intensif Anak Ilmu Kesehatan Anak (ERIA IKA) Rumah Sakit Umum Pusat Nasional Cipto Mangunkusumo (RSUPN CM) sejak tahun 2017 sudah menggunakan skor PELOD-2 untuk memprediksi luaran perawatan pasien sakit kritis yang dirawat di PICU. Namun dalam penerapannya, hasil skor PELOD-2 tidak selalu berbanding lurus dengan luaran perawatan anak sakit kritis. Penelitian ini bertujuan untuk mendeskripsikan karakteristik pasien sakit kritis yang dirawat di PICU RS. Cipto Mangunkusumo berdasarkan profil skor PELOD-2 dan hubungannya dengan luaran perawatan pasien sakit kritis yang dirawat di PICU, serta mengevaluasi kemungkinan penyebab ketidaksesuaian skor PELOD-2 dengan luaran pasien sakit kritis.

\section{Metode}

Penelitian ini bersifat deskriptif analitik dengan menggunakan data rekam medis pasien PICU RS Cipto Mangunkusumo, Jakarta sejak Januari 2018 sampai Desember 2019. Kriteria inklusi subjek penelitian adalah berusia lebih dari 28 hari dan kurang dari 18 tahun, mengalami sakit kritis dan pasien pasca-operasi yang di rawat di PICU RSUPN CM. Kriteria eksklusi adalah data pemeriksaan skor PELOD-2 tidak lengkap. Nilai skor PELOD-2 langsung diambil dalam 1×24 jam saat pasien dirawat di PICU RSUPN CM dan dicantumkan dalam data rekam medis. Data subjek diambil dari rekam medis pasien meliputi identitas pasien, status gizi, komorbid penyerta, diagnosis, tanda-tanda vital (kesadaran, laju nadi, tekanan darah, laju napas, dan suhu), nilai skor PELOD-2, lama rawat di ruang intensif, dan luaran mortalitas.

Analisis data menggunakan program SPSS 20.0. Skor PELOD-2 dikelompokkan menjadi skor $\leq 11$ dan skor $>11$ sesuai kriteria sepsis untuk fasilitas kesehatan tersier. Lama rawat dikelompokkan menjadi $>7$ hari dan $\leq 7$ hari sesuai dengan penelitian sebelumnya, sebagai salah satu titik optimal penilaian skor PELOD-2 kontinyu. Analisis bivariat dilakukan dengan uji chi square atau uji Fisher Exact. Perhitungan resiko relatif untuk rancangan penelitian potong lintang berupa angka rasio prevalensi (prevalence ratio, $\mathrm{PR}$ ).

\section{Hasil}

Terdapat 650 pasien anak sakit kritis yang dirawat di PICU RSUPN CM, 173 pasien tidak memiliki data PELOD-2 yang lengkap sehingga hanya 477 pasien anak yang diikutsertakan menjadi subjek penelitian.

Subjek sebagian besar berjenis kelamin laki-laki $(56,4 \%)$ dan berusia $<1$ tahun (27,9\%), dengan bedah sebagai diagnosis awal terbanyak (65\%). Sebagian besar pasien memiliki penyakit kronik (70,4\%). Angka mortalitas pasien anak sakit kritis yang dirawat di PICU RSUPN CM periode Januari-Desember 2018 adalah $10,7 \%$. Sebagian besar pasien anak sakit kritis yang 
dirawat di PICU RSUPN CM memiliki lama rawat $\leq 7$ hari $(75,5 \%)$ (Tabel 1$)$.

Subjek dengan skor PELOD-2 $<7$ sebagian besar memiliki luaran hidup $(96,1 \%)$ dan lama rawat $\leq 7$ hari (79,6\%). Subjek dengan skor PELOD-2 >11 sebagian besar memiliki luaran meninggal $(93,8 \%)$ dan lama rawat $>7$ hari $(56,3 \%)$ (Tabel 2$)$.

Semakin banyak disfungsi organ suatu subjek makin besar skor PELOD-2. Median skor PELOD-2 10 memiliki 4 sistem organ yang mengalami disfungsi.

Subjek dengan skor PELOD-2 $<11$ sebagian besar memiliki luaran hidup (99,8\%), tetapi didapatkan 36 (70,6\%) subjek meninggal memiliki skor PELOD-2 $\leq 11$. Hasil uji korelasi menggunakan uji Chi square didapatkan subjek dengan skor PELOD-2 $\leq 11$ memiliki risiko 12 kali lipat untuk mengalami luaran meninggal daripada subjek dengan skor PELOD-2 $>11$ (Tabel 3).

Subjek dengan skor PELOD-2 $\leq 11$ sebagian besar memiliki lama rawat $\leq 7$ hari $(98,1 \%)$, tetapi didapatkan 108 (92,3\%) subjek dengan skor PELOD-2 $\leq 11$ memiliki lama rawat $>7$ hari. Hasil uji korelasi menggunakan uji Chi square didapatkan subjek dengan skor PELOD-2 $\leq 11$ memiliki risiko 2,4 kali lipat untuk mengalami lama rawat $>7$ hari daripada subjek dengan skor PELOD-2 >11 (Tabel 4). Hal ini tidak sesuai dengan teori sebelumnya sehingga peneliti melakukan analisis lebih lanjut dengan uji bivariat. Dilakukan analisis Chi Square atau uji Fisher Exact untuk menguji hipotesis variabel independen dengan variabel dependen. Perhitungan resiko relatif untuk berupa angka rasio prevalensi (prevalence ratio, PR).

Dari hasil uji didapatkan status nutrisi, keganasan dan penyakit kronik tidak berhubungan dengan luaran meninggal pada subjek dengan skor PELOD-2 $<11$, sementara pada imunosupresi didapatkan adanya hubungan $(\mathrm{p}=0,006)$. Namun, jumlah sampel tidak terpenuhi sehingga kekuatan penelitian tidak mencapai 80. Dari analisis luaran lama rawat didapatkan status nutrisi, imunosupresi, dan adanya keganasan berhubungan dengan lama rawat $(\mathrm{p}<0,05)$, sementara untuk penyakit kronik tidak didapatkan hubungan $(\mathrm{p}=0,424)$. Subjek dengan status gizi buruk memiliki risiko 2 kali lipat untuk menjalani masa perawatan $>7$ hari (IK 95\% 1,433-2,814) dibandingkan subjek dengan status nutrisi yang lain. Subjek dengan imunosupresi memiliki risiko 1,557 kali lipat untuk mengalami masa perawatan $>7$ hari (IK 95\% 1,078-2,249) dibandingkan subjek tanpa imunosupresi. Sementara itu, subjek tanpa keganasan memiliki risiko 0,5 kali lipat menjalani masa perawatan $>7$ hari (IK 95\%: 0,348-0,972) dibandingkan dengan subjek dengan keganasan.

Nilai AUC skor PELOD-2 dari kurva ROC untuk

Tabel 1. Karakteristik subjek penelitian

\begin{tabular}{|c|c|}
\hline Karakteristik & Jumlah, n (\%) \\
\hline \multicolumn{2}{|l|}{ Jenis kelamin, $\mathrm{n}(\%)$} \\
\hline Laki-laki & $269(56,4)$ \\
\hline Perempuan & $208(43,6)$ \\
\hline \multicolumn{2}{|l|}{ Usia, n (\%) } \\
\hline$<1$ tahun & $133(27,9)$ \\
\hline $1-5$ tahun 11 bulan & $122(25,6)$ \\
\hline 6-9 tahun 11 bulan & $88(18,4)$ \\
\hline 10-15 tahun & $97(20,3)$ \\
\hline$>15$ tahun & $37(7,8)$ \\
\hline \multicolumn{2}{|l|}{ Diagnosis masuk, n (\%) } \\
\hline Medis & $167(35,0)$ \\
\hline Bedah & $310(65,0)$ \\
\hline \multicolumn{2}{|l|}{ Status nutrisi } \\
\hline Gizi buruk & $82(17,2)$ \\
\hline Gizi kurang & $110(23,1)$ \\
\hline Gizi baik & $256(53,7)$ \\
\hline Gizi lebih & $17(3,6)$ \\
\hline Obesitas & $12(2,5)$ \\
\hline \multicolumn{2}{|l|}{ Disfungsi organ, $\mathrm{n}(\%)$} \\
\hline Neurologi & $99(20,75)$ \\
\hline Respirasi & $74(15,51)$ \\
\hline Kardiovaskular & $99(20,75)$ \\
\hline Renal & $62(12,99)$ \\
\hline Hematologi & $336(41,72)$ \\
\hline Sepsis, n (\%) & $99(20,8)$ \\
\hline Penyakit kronik, n (\%) & $336(70,4)$ \\
\hline Terapi imunosupresan, n (\%) & $80(16,8)$ \\
\hline Keganasan, n (\%) & $99(20,8)$ \\
\hline Transplantasi organ, n (\%) & $20(4,2)$ \\
\hline \multicolumn{2}{|l|}{ Luaran, n (\%) } \\
\hline Lama rawat $\leq 7$ hari & $360(75,5)$ \\
\hline Lama rawat $8-14$ hari & $71(14,9)$ \\
\hline Lama rawat > 14 hari & $46(9,6)$ \\
\hline \multicolumn{2}{|l|}{ Mortalitas, n (\%) } \\
\hline Meninggal & $51(10,7)$ \\
\hline Hidup & $426(89,3)$ \\
\hline \multicolumn{2}{|l|}{ Katagori PELOD } \\
\hline$<7$ & $411(86,2)$ \\
\hline $7-11$ & $50(10,5)$ \\
\hline$>11$ & $16(3,4)$ \\
\hline
\end{tabular}


Tabel 2. Skor PELOD-2 dan luaran

\begin{tabular}{lcccc}
\hline \multirow{2}{*}{$\begin{array}{l}\text { Skor } \\
\text { PELOD-2 }\end{array}$} & \multicolumn{2}{c}{ Luaran } & \multicolumn{2}{c}{ Lama rawat } \\
\cline { 2 - 5 } & Meninggal $(\mathrm{n}, \%)$ & Hidup $(\mathrm{n}, \%)$ & $>7$ hari $(\mathrm{n}, \%)$ & $\leq 7$ hari $(\mathrm{n}, \%)$ \\
\hline$<7$ & $16(3,9)$ & $395(96,1)$ & $84(20,4)$ & $327(79,6)$ \\
$7-11$ & $20(40)$ & $30(60)$ & $24(48)$ & $26(52)$ \\
$>11$ & $15(93,8)$ & $1(6,2)$ & $9(56,2)$ & $7(43,8)$ \\
\hline
\end{tabular}

Tabel 3. Hubungan skor PELOD-2 dengan luaran subjek

\begin{tabular}{|c|c|c|c|c|}
\hline \multirow{2}{*}{ Variabel } & \multicolumn{2}{|c|}{ Luaran, n (\%) } & \multirow{2}{*}{ PR (IK 95\%) } & \multirow[b]{2}{*}{$\mathrm{p}$} \\
\hline & meninggal & hidup & & \\
\hline \multicolumn{5}{|c|}{ Skor PELOD-2 } \\
\hline$>11$ & $15(29,4)$ & $1(0,2)$ & $12,005(8,560-16,836)$ & $<0,001$ \\
\hline$\leq 11$ & $36(70,6)$ & $425(99,8)$ & & \\
\hline
\end{tabular}

Tabel 4. Hubungan skor PELOD-2 dengan lama rawat subjek

\begin{tabular}{|c|c|c|c|c|}
\hline \multirow{2}{*}{ Variabel } & \multicolumn{2}{|c|}{ Lama rawat, n (\%) } & \multirow{2}{*}{ PR (IK 95\%) } & \multirow[b]{2}{*}{$\mathrm{p}$} \\
\hline & $>7$ hari & $\leq 7$ hari & & \\
\hline \multicolumn{5}{|c|}{ Skor PELOD-2 } \\
\hline$>11$ & $9(7,7)$ & $7(1,9)$ & $2,401(1,512-3,813)$ & $<0,006$ \\
\hline$\leq 11$ & $108(92,3)$ & $353(98,1)$ & & \\
\hline
\end{tabular}

luaran meninggal adalah 93,4\% (IK 95\%: 90,6-96,2). Titik potong pada kurva di angka 4,5 dan ditunjukkan pada koordinat skor PELOD-2 bernilai $\geq 5$ yang berarti skor PELOD-2 $\geq 5$ memiliki sensitivitas dan spesifisitas berturut-turut $84,3 \%$ dan $84,5 \%$.

Untuk luaran meninggal pada subjek dengan sepsis, nilai AUC skor PELOD-2 dari kurva ROC adalah sebesar 84,2\% (IK 95\%: 76,1-92,3). Titik potong pada kurva di angka 6,5 dan ditunjukkan pada koordinat skor PELOD-2 bernilai $\geq 7$ yang berarti PELOD-2 $\geq 7$ memiliki sensitivitas $77,1 \%$ dan spesifisitas $75 \%$.

\section{Pembahasan}

Subjek pasien anak laki-laki sakit kritis lebih banyak dibanding perempuan $(56,4 \%)$. Suatu studi mendapatkan bahwa jenis kelamin akan membedakan respon imun, subjek laki-laki lebih sering mengalami kondisi penyakit yang lebih berat akibat adanya peningkatan mediator pro inflamasi, yaitu TNF, IL-6, IL-10, dan pada subjek perempuan ternyata ditemukan lebih banyak mediator anti inflamasi. ${ }^{10}$
Usia 1-11 bulan merupakan subjek terbanyak $(27,9 \%)$ dari kelompok usia lainnya. Beberapa studi sebelumnya mengenai skor PELOD-2, menemukan bahwa kelompok usia pasien sakit kritis terbanyak pada rentang 1-11 bulan diikuti kelompok usia 1 tahun $-<2$ tahun dan usia $2-<5$ tahun. Hal ini disebabkan karena anak usia $<5$ tahun masih sangat rentan terhadap kejadian infeksi hingga sepsis akibat sistem imun pejamu yang belum matang. ${ }^{11,12}$

Pasien yang dirawat dengan diagnosis awal bedah lebih banyak. Hal ini mungkin disebabkan lama perawatan pasien bedah lebih sedikit daripada pasien medis sehingga memiliki turn over yang lebih besar.

Lebih dari setengah jumlah subjek penelitian memiliki status gizi baik, dengan $23,1 \%$ gizi kurang dan $17,2 \%$ subjek gizi buruk. Diperberat dengan kondisi hipermetabolisme dan peningkatan katabolisme pada sepsis mengakibatkan anak dengan kekurangan gizi lebih sering mengalami disfungsi organ. ${ }^{12,13}$ Sebagian besar subjek memiliki status gizi baik mungkin terkait dengan status nutrisi optimal sebagai salah satu syarat prabedah.

Sebagian besar pasien anak sakit kritis yang dirawat di PICU RSCM memiliki penyakit kronik (70,4\%). Penelitian di Amerika mengenai penyakit 
kronik pada pasien anak sakit kritis yang dirawat di PICU didapatkan 53\% pasien menderita penyakit kronik sebagai komorbid. Penelitian tersebut juga mendapatkan risiko mortalitas dan lama rawat yang lebih tinggi dibandingkan pasien anak sakit kritis yang tidak memiliki penyakit kronik sebelumnya. ${ }^{14}$

Selama kurun waktu penelitian diperoleh data anak dengan disfungsi organ hematologi yang paling banyak ditemukan (41,72\%), lalu kardiovaskular $(20,75 \%)$, dan neurologi $(20,75 \%)$. Hal ini berbeda dengan beberapa studi yang dilakukan di PICU RS lain, yaitu sejumlah 46,6\% mengalami disfungsi organ respirasi. ${ }^{15}$ Penelitian ini mungkin memiliki subjek dengan manifestasi MODS tahap akhir sehingga disfungsi hematologi merupakan temuan paling banyak.

Sebagian besar pasien anak sakit kritis yang dirawat di PICU RSUP CM mengalami lama rawat $<7$ hari $(75,5 \%)$ dan hanya $9,6 \%$ yang mengalami perawatan $>14$ hari di PICU RSCM. Subjek dengan skor PELOD-2 $<7$ sebagian besar memiliki lama rawat $\leq 7$ hari $(79,6 \%)$, sedangkan subjek dengan skor PELOD-2 $>11$ sebagian besar memiliki luaran lama rawat $>7$ hari $(56,3 \%)$. Keadaan ini sesuai dengan hasil penelitian terdahulu, yaitu semakin tinggi nilai skor PELOD-2 maka makin banyak sistem organ yang mengalami disfungsi diikuti dengan peningkatan kemungkinan untuk mengalami kematian semakin besar. ${ }^{6,8,16}$

Prediksi dari kemungkinan kematian disebut predicted death rate (PDR). Nilai PDR sudah diketahui pada pasien sakit kritis yang dinilai dengan skor PELOD-2. Median skor PELOD-2 10 memiliki 4 sistem organ yang mengalami disfungsi dan memiliki rerata kemungkinan kematian sebesar 29,5 (SB 32,88). Kondisi yang serupa juga ditemui pada penelitian yang dilakukan Leteurte, ${ }^{8}$ yaitu dengan rerata skor PELOD-2 9,78 (SB 4,81) ditemukan tiga sistem organ yang mengalami disfungsi dengan kematian 21,9\% (SB 33,03).

Angka kematian keseluruhan dalam penelitian adalah $10,7 \%$. Penelitian yang dilakukan oleh Leteurte ${ }^{8}$ dan Garcia ${ }^{16}$ menunjukkan angka kematian yang lebih kecil, yaitu 4,7-6,1\%.' Kondisi ini berkaitan dengan status RSCM sebagai pusat rujukan nasional sehingga kasus yang datang adalah kasus yang sangat berat.

Subjek dengan skor PELOD-2 yang lebih tinggi memiliki nilai prediksi mortalitas yang lebih tinggi dan atau lama rawat yang lebih lama. Hal ini sesuai dengan hasil penelitian, 425 (99,8\%) subjek yang hidup memiliki skor PELOD-2 $\leq 11$ dan 353 (98,1\%) subjek dengan lama rawat $\leq 7$ hari memiliki skor PELOD-2 $\leq 11$. Namun, didapatkan $36(70,6 \%)$ subjek meninggal memiliki skor PELOD- $\leq 11$. Hasil uji korelasi menggunakan uji Chi square mendapatkan subjek dengan skor PELOD-2 $\leq 11$ memiliki risiko 12 kali lipat untuk mengalami luaran meninggal daripada subjek dengan skor PELOD-2 $>11$. Dari analisis didapatkan 108 (92,3\%) subjek dengan skor PELOD-2 $\leq 11$ memiliki lama rawat $>7$ hari. Hasil uji korelasi menggunakan uji Chi square didapatkan subjek dengan skor PELOD- $\leq 11$ memiliki risiko 2,4 kali lipat untuk mengalami lama rawat $>7$ hari daripada subjek dengan skor PELOD-2 $>11$. Hasil ini tidak sesuai dengan teori sebelumnya, sehingga dilakukan untuk mengetahui ada tidaknya hubungan antara skor PELOD-2 terutama dengan faktor yang belum diperhitungkan dalam skor PELOD maupun PELOD-2 (status nutrisi, status imunitas, adanya morbiditas yang memengaruhi status imunitas seperti keganasan dan penyakit kronik, dan faktor genetik). Data rekam medis tidak menyertakan faktor genetik sehingga tidak dilakukan analisis lebih lanjut. Status imunitas subjek dinilai berdasarkan klinis sesuai batasan operasional yang telah ditetapkan sebelumnya.

Status nutrisi tidak berhubungan dengan luaran meninggal pada subjek dengan skor PELOD- $\leq 11$, serta tidak berhubungan dengan lama rawat subjek dengan skor PELOD- $2 \geq 11$. Namun, jumlah sampel tidak terpenuhi sehingga kekuatan penelitian tidak mencapai 80. Status nutrisi subjek dengan skor PELOD- $2<11$ berhubungan dengan lama rawat. Hasil ini sesuai dengan penelitian yang dilakukan oleh Menezes ${ }^{14}$ yang melaporkan adanya malnutrisi berhubungan dengan lama penggunaan ventilasi mekanik dan lama perawatan PICU, tetapi tidak berhubungan dengan mortalitas. Sebuah penelitian mendapatkan pasien dengan malnutrisi masih memproduksi marker inflamasi, seperti CRP dan IL-6, tetapi tidak sebesar pasien tanpa malnutrisi. ${ }^{17}$

Adanya imunosupresi pada subjek dengan skor PELOD- $<11$ berhubungan dengan luaran meninggal. Gangguan pada status imun pejamu menyebabkan pejamu tidak optimal menghadapi pajanan dari luar, menyebabkan respon sistemik yang tidak adekuat. Pasien sakit kritis terutama dengan sepsis juga dapat menyebabkan imunoparalisis, menyebabkan komplikasi dan infeksi sekunder yang akan berpengaruh dengan luaran pasien. ${ }^{18}$ Penilaian status imun subjek pada penelitian ini hanya berdasarkan klinis dan 
belum dilakukan secara objektif dengan pemeriksaan immunoglobulin dan profil limfosit subset sehingga perlu dilakukan penelitian lebih lanjut menggunakan pemeriksaan objektif untuk hasil yang lebih akurat.

Penyakit kronik sebagai komorbid tidak berhubungan baik dengan dengan lama rawat subjek maupun dengan luaran meninggal pada subjek dengan skor PELOD- $\leq 11$. Namun, jumlah sampel tidak terpenuhi sehingga kekuatan penelitian tidak mencapai 80. Penelitian di Amerika mengenai penyakit kronik pada pasien anak sakit kritis yang dirawat di PICU menyimpulkan adanya hubungan penyakit kronik dengan mortalitas yang lebih tinggi dan lama rawat yang lebih lama. ${ }^{19}$ Sistem skoring pasien sakit kritis yang ada saat ini belum mempertimbangkan kondisi kronik pasien secara penuh.

Keganasan pada subjek dengan skor PELOD-2 $<11$ berhubungan dengan lama rawat, tetapi tidak berhubungan dengan luaran meninggal pada subjek dengan skor PELOD- $\leq 11$ maupun subjek dengan skor PELOD-2 $>11$. Penelitian serupa mendapatkan tidak ada perbedaan luaran mortalitas dan lama rawat meskipun didapatkan lebih banyak disfungsi organ pada pasien dengan keganasan. ${ }^{20}$

Luaran mortalitas dan lama rawat subjek yang tidak sesuai dengan skor PELOD-2 kemungkinan dipengaruhi oleh faktor pejamu yang belum diperhitungkan dalam skor PELOD-2. Faktor pejamu yang belum bermanifestasi atau belum menyebabkan disfungsi organ tidak akan terdeteksi sehingga skor PELOD-2 pasien akan rendah. Penelitian ini mendapatkan status nutrisi dan status imun subjek berpengaruh terhadap luaran mortalitas dan lama rawat sehingga menyebabkan ketidaksesuaian skor PELOD-2 pada sebagian subjek, sehingga perlu dilakukan penelitian lebih lanjut dengan desain kohort multisenter dengan jumlah sampel lebih besar.

Median skor PELOD-2 subjek yang meninggal pada penelitian ini adalah delapan, lebih rendah dari titik potong skor PELOD-2 yang digunakan pada penelitian ini (11). PDR untuk skor PELOD-2 11 adalah $30,5 \%$, tetapi pada penelitian ini terdapat $93,75 \%$ subjek dengan skor PELOD-2 >11 yang mengalami luaran meninggal. Hal ini mungkin disebabkan dengan status RSCM sebagai pusat rujukan nasional, sehingga kasus yang datang adalah kasus yang sangat berat dengan komorbid subjek yang lebih berat.

Nilai AUC skor PELOD-2 dari kurva adalah sebesar 93,4\% (IK 95\%: 90,6-96,2) sehingga dianggap baik untuk membedakan luaran meninggal. Kurva ROC menunjukkan bahwa skor PELOD-2 memiliki nilai diagnosis yang baik karena kurva menjauhi garis $50 \%$ dan mendekati $100 \%$, artinya apabila skor PELOD-2 digunakan untuk mendiagnosis 100 anak akan mengalami luaran meninggal maka kesimpulan yang tepat akan diperoleh pada 93,4 pasien.

Perhitungan PDR untuk skor PELOD-2 5 adalah $1,5 \%$, perbedaan ini mungkin karena subjek penelitian ini memiliki karakteristik yang lebih beragam dibandingkan dengan penelitian-penelitian sebelumnya.

Beberapa keterbatasan dalam penelitian ini, yaitu pelaksanaan penelitian ini terbatas pada satu rumah sakit tersier (single centre) sehingga belum dapat mewakili data karakteristik pasien anak sakit kritis di Indonesia. Penelitian ini belum dapat mengevaluasi faktor-faktor yang memengaruhi performa skor PELOD-2. Kelebihan penelitian ini dapat memberikan gambaran performa sistem skoring PELOD-2 dan profil pasien sakit kritis di fasilitas kesehatan tersier. Hasil penelitian ini diharapkan dapat menjadi hipotesis bagi penelitian selanjutnya yang diharapkan dapat mengevaluasi faktor pejamu yang mungkin memengaruhi performa skor PELOD-2.

\section{Kesimpulan}

Skor PELOD-2 dapat digunakan untuk memprediksi disfungsi organ yang mengancam kehidupan pada anak tanpa imunosupresi dan semakin tinggi skor PELOD-2 akan diikuti dengan peningkatan lama rawat dan mortalitas. Skor PELOD-2 $\geq 5$ merupakan titik potong skor PELOD-2 untuk luaran meninggal subjek secara keseluruhan, dan skor $\geq 7$ yang merupakan titik potong skor PELOD-2 untuk luaran meninggal subjek dengan sepsis.

\section{Daftar pustaka}

1. Tantaleán JA, León RJ, Santos AA, Sánchez E. Multiple organ dysfunction syndrome in children. Pediatr Crit Care Med 2003;4:2-9.

2. Proulx F, Joyal JS, Mariscalco MM, dkk. The pediatric multiple organ dysfunction syndrome. Pediatr Crit Care Med 2009;10:12-22.

3. Marcin JP, Pollack MM. Review of the acuity scoring systems 
for the pediatric intensive care unit and their use in quality improvement. J Intensive Care Med 2007;22:131-40.

4. Vincent JL, Ferreira F, Moreno R. Scoring systems for assessing organ dysfunction and survival. Crit Care Clin 2000;2:353-66.

5. Seymour CW, Liu VX, Iwashyna TJ, Brunkhorst FM, Rea TD, Scherag A, dkk. Assessment of clinical criteria for sepsis for the third international consensus definitions for sepsis and septic shock (Sepsis-3). JAMA 2016;315:762-74.

6. Leteurtre S, Martinot A, Duhamel A, Proulx F, Grandbastein B, Cotting J, dkk. Validation of the pediatric logistic organ dysfunction (PELOD) score: prospective, observational, multicentre study. Lancet 2003;362:192-7.

7. Metta D, Soebardja D, Somasetia DH. The use of pediatric logistic organ dysfunction (PELOD) scoring system to determine prognosis of patient in pediatric intensive care unit. Paediatrica Indones 2006;46:1-6.

8. Leteurtre S, Duhamel A, Salleron J, Grandbastien B, Lacroix J, Leclerc F, and the Groupe Francophone de Réanimation et d'Urgences Pédiatriques. PELOD-2: An update of the pediatric logistic organ dysfunction score. Crit Care Med 2013;41:176173.

9. Suari NMR. Validitas skor PELOD-2 pada anak dengan sepsis di Rumah Sakit Umum Pusat Nasional Cipto Mangunkusumo, Tesis. Jakarta: Universitas Indonesia; 2017.

10. Angele MK, Pratschke S, Hubbard WJ, Chaudry IH. Gender differences in sepsis: Cardiovascular and immunological aspects. Virulence 2014;5:12-9.

11. Latief A. Support nutrisi pada anak dengan sepsis. Dalam: Lubis M, Evalina R, Irsa, penyunting. Makalah lengkap simposium nasional pediatri gawat darurat VI. Medan. Bagian Ilmu Kesehatan Anak FK USU; 2003.h.86-103.
12. Wynn J, Cornell TT, Wong HR, Shanley TP, Wheeler DS. The host response to sepsis and developmental impact. Pediatrics 2010;125:1031-41.

13. Keusch GT. The History of Nutrition: Malnutrition, Infection and Immunity. J Nutr 2003:336S-40S.

14. Menezes FS, Nogueira PCK. Malnutrition as an independent predictor of clinical outcome in critically ill children. Nutrition 2012;28:267-70.

15. Leteurtre S, Duhamel A, Grandbastien B, Proulx F, Cotting J, Gottesman R, dkk. Daily estimation of the severity of multiple organ dysfunction syndrome in critically ill children. CMAJ 2010:1181-7.

16. Garcia PC, Eulmesekian P, Branco RG, Perez A, Sffogia A, Oliveo L, dkk. External validation of the paediatric logistic organ dysfunction score. Intensive Care Med 2010;36:116-22.

17. Delgado AF, Okay TS, Leone C, Nichols B. Hospital malnutrition and inflammatory response in critically ill children and adolescents admitted to a tertiary intensive care unit. Clinics 2008;63:357-62.

18. Edwards JD, Houtrow AJ, Vasilevskis EE, Rehm RS, Markovitz BP. Chronic conditions among children admitted to US PICUs: their prevalence and impact on risk for mortality and prolonged length of stay. Crit Care Med 2012;40:2196-22-3.

19. Pound CM, Johnston DL, Armstrong R, Gaboury I, Menon $\mathrm{K}$. The morbidity and mortality of pediatric oncology patients presenting to the intensive care unit with septic shock. Pediatr Blood Cancer 2008;51:584-8.

20. Pound CM, Johnston DL, Armstrong R, Gaboury I, Menon $\mathrm{K}$. The morbidity and mortality of pediatric oncology patients presenting to the intensive care unit with septic shock. Pediatr Blood Cancer 2008;51:584-8. 